\title{
Effect of Idebenone (CV-2619) on Memory Impairment Observed in Passive Avoidance Task in Rats with Cerebral Embolization
}

\author{
Yoshihiro KIYOTA, Kazuhiro HAMAJO, Masaomi MIYAMOTO \\ and Akinobu NAGAOKA \\ Biology Laboratories, Central Research Division. Takeda Chemical Industries, Ltd., \\ Yodogawa-ku, Osaka 532, Japan
}

Accepted December 26, 1984

\begin{abstract}
Effect of idebenone (CV-2619) on memory impairment was studied in rats with cerebral embolization. The cerebral embolization, produced by injecting 2000 microspheres into the internal carotid artery, caused a significant impairment in passive avoidance response. Repeated administrations of idebenone ( $30 \mathrm{mg} /$ $\mathrm{kg} /$ day, i.p.). partially but significantly improved the impairment of the passive avoidance response in the embolized rats. The results suggest that the repeated administration of idebenone exerts an ameliorating effect on memory impairment induced by cerebral embolization.
\end{abstract}

Idebenone (CV-2619), 6-(10-hydroxydecyl)-2,3-dimethoxy-5-methyl-1,4-benzoquinone, is a novel compound that has an effect on cerebral ischemic disorder: a decrease in ATP content and an increase in lactate content induced by brain ischemia following bilateral carotid artery occlusion in stroke-prone spontaneously hypertensive rats were significantly inhibited by idebenone (1). The drug also showed an improving action on the impairment of passive avoidance response induced by a transient cerebral ischemia in rats (2). These effects of idebenone might be related to the improvement of brain energy metabolism and/or inhibition of lipid peroxidation (1,3). In the present study, the effect of idebenone on memory impairment was studied in rats with cerebral embolization which was produced by an injection of solid microspheres into the internal carotid artery.

Male JCL: Wistar rats weighing 250-300 g at the start of the experiment were used. The embolization was performed according to the method described by Kogure et al. (4) with minor modifications. The rats were anesthetized with ethyl ether, and the left carotid artery bifurcation was exposed. The left external carotid and pterygo-palatine arteries were ligated. PE-50 polyethylene tubing filled with saline was inserted into the common carotid artery via the external carotid artery. Two thousand carbon microspheres (35 $\pm 5 \mu \mathrm{m}$ in diameter), suspended in $50 \mu \mathrm{l}$ of $20 \%$ dextran, were injected into the internal carotid artery through the tubing. Sham-operated rats were injected with the same volume of $20 \%$ dextran instead of microsphere suspension.

The acquisition trial in passive avoidance task was carried out after a 7 -day recovery period from the operation. The rats were placed in an illuminated compartment $(25 \times 10 \times 25 \mathrm{~cm})$ and allowed to enter a large dark compartment $(30 \times 30 \times 30 \mathrm{~cm})$ equipped with a grid floor. As soon as the rats entered the dark compartment, the door which separates the two compartments was closed and unescapable footshock (2.5 mA, $3 \mathrm{sec})$ was delivered through the grid floor. In the retention test performed $24 \mathrm{hr}$ after the acquisition trial, the rats were again placed in the illuminated compartment, and the response latency to enter the dark compartment was measured. If the rat avoided longer than $300 \mathrm{sec}$, a ceiling score of $300 \mathrm{sec}$ was assigned.

In the experiment to study acute effects of drugs on the passive avoidance response, idebenone, physostigmine (PHY), arecoline (ARE) or arginine-vasopressin (AVP) was 
administered to the embolized rats immediately after the acquisition trial and $30 \mathrm{~min}$ prior to the retention test. On the other hand, the chronic effect of idebenone was assessed by daily administration (10 or $30 \mathrm{mg} / \mathrm{kg} /$ day, i.p.) from the embolization day ( $4 \mathrm{hr}$ after the operation) to the retention test day. On the acquisition trial day and the retention test day, idebenone was administered immediately after the acquisition trial and 30 min prior to the retention test. The chronic treatment seemed to be more effective than the acute treatment because idebenone was expected to inhibit metabolic changes in ischemic cerebral tissues induced by the embolization. Statistical comparison between different groups was made using the MannWhitney $U$-test.

In most of the sham-operated rats, the response latency to enter the dark compartment was nearly $300 \mathrm{sec}$ in the retention test. In contrast, the response latency in the rats with cerebral embolization was very short, ranging from 20 to $50 \mathrm{sec}$. This finding indicates that passive avoidance response is impaired by the cerebral embolization.

Two administrations of idebenone (10 or $30 \mathrm{mg} / \mathrm{kg}$, i.p.) showed no significant effect on the impairment of passive avoidance response in the embolized rats, although the mean response latency was prolonged (Fig. 1A). In another experiment, the effect of a higher dose of idebenone $(100 \mathrm{mg} / \mathrm{kg}$, i.p.) was also assessed, whereas the effect was not significant (vehicle control: $21.6 \pm 8.0 \mathrm{sec}$; idebenone, $100 \mathrm{mg} / \mathrm{kg}$, i.p.: $51.7 \pm 26.8 \mathrm{sec}$ ). However, when idebenone (10 or $30 \mathrm{mg} / \mathrm{kg} /$ day, i.p.) was repeatedly given once daily from the embolization day to the retention test day, the response latency was prolonged in a dose-dependent manner, and the effect of the higher dose was statistically significant as compared with the vehicle-treated control (Fig. 1B).
(A)

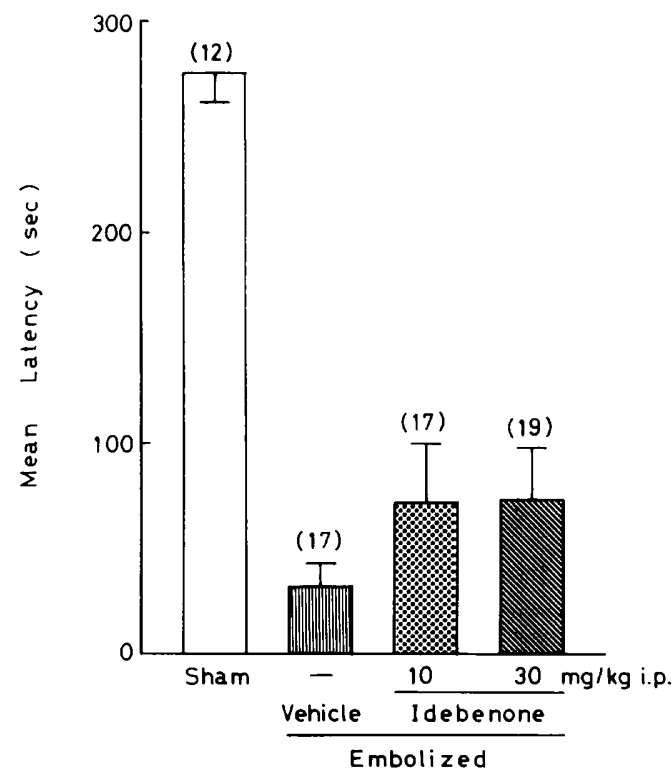

(B)

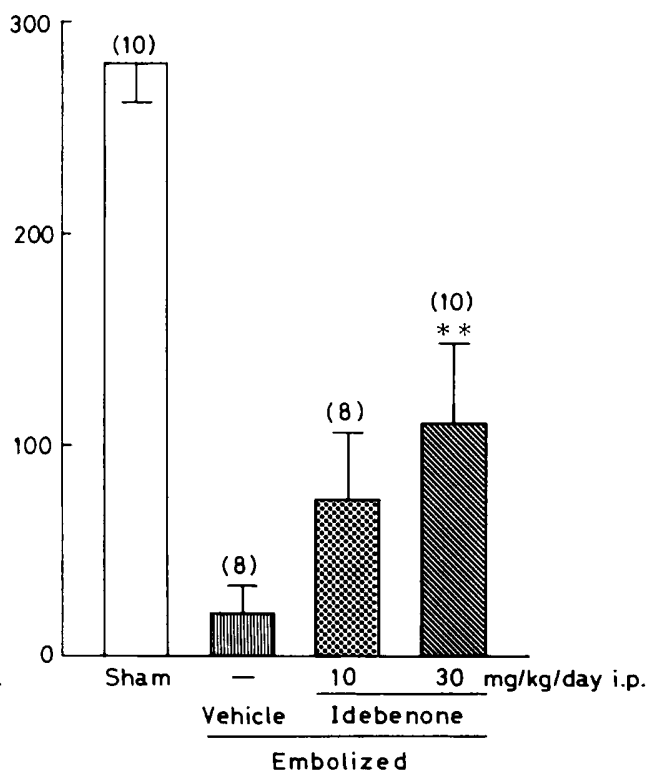

Fig. 1. Effect of idebenone on impairment of passive avoidance response in the embolized rats. Idebenone (10 or $30 \mathrm{mg} / \mathrm{kg}$, i.p.) was given immediately after the acquisition trial and 30 min prior to the retention test (A), or it was given repeatedly once daily from the embolization day to the retention test day (B). The acquisition trial was done 7 days after the operation. The retention test was performed $24 \mathrm{hr}$ after the acquisition trial. Each value is the mean \pm S.E. (sec). Number of rats is shown in parentheses. Vehicle: $5 \%$ gum arabic $\left(0.2 \mathrm{ml} / 100 \mathrm{~g}\right.$ body weight, i.p.) ${ }^{*} \mathrm{P}<0.01$, compared with the vehicle-treated control. 


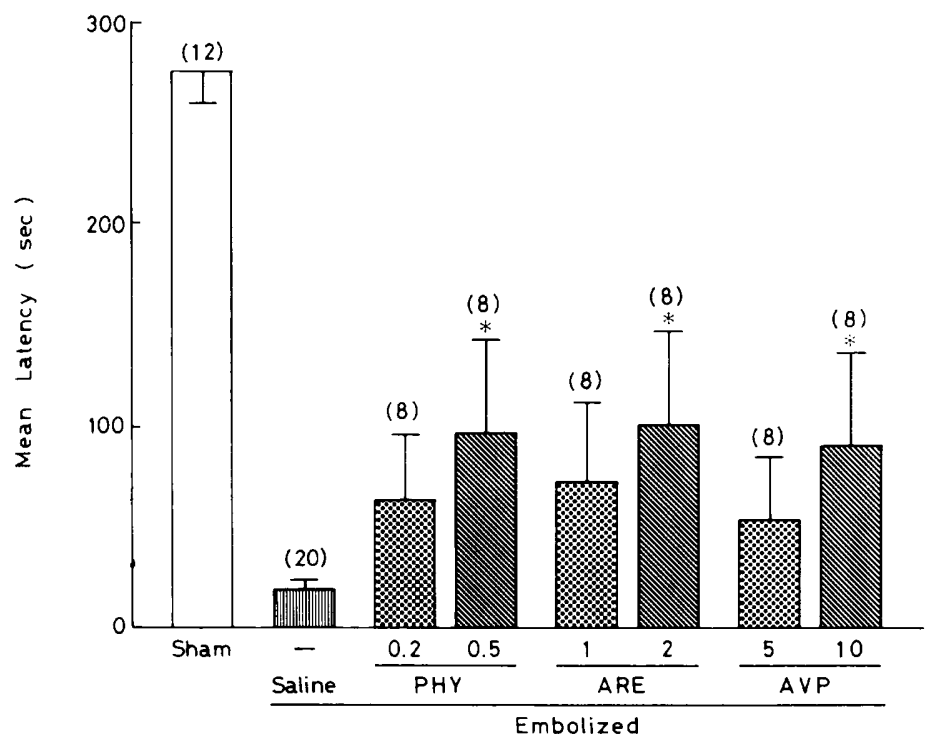

Fig. 2. Effects of drugs on impairment of passive avoidance respcnse in the embolized rats. Physostigmine (PHY: 0.2 or $0.5 \mathrm{mg} / \mathrm{kg}$, i.p.), arecoline (ARE: 1.0 or $2.0 \mathrm{mg} / \mathrm{kg}$, i.p.) or arginine-vasopressin (AVP: 5 or $10 \mu \mathrm{g} /$ body, s.c.) was given immediately after the acquisition trial and 30 min prior to the retention test. The acquisition trial was done 7 days after the operation. The retention test was performed 24 hr after the acquisition trial. Each value is the mean \pm S.E. (sec). Number of rats is shown in parentheses. ${ }^{*} \mathrm{P}<0.05$, compared with the saline control.

The shortened response latency in rats with the cerebral embolization was prolonged by $\mathrm{PHY}(0.2$ or $0.5 \mathrm{mg} / \mathrm{kg}$, i.p.), ARE $(1.0$ or $2.0 \mathrm{mg} / \mathrm{kg}$, i.p.) and AVP ( 5 or $10 \mu \mathrm{g} /$ body, s.c.) in a dose-dependent manner. Significant effects were observed at a higher dose of these drugs (Fig. 2).

Thus, idebenone administered chronically showed a dose-dependent ameliorating effect on the impairment of passive avoidance response in rats with cerebral embolization. PHY, ARE and AVP, which have been reported to improve memory disturbances in different types of animal models (5-7), also showed a significant prolongation of the response latency in the embolized rats.

From these findings, it is suggested that repeated administration of idebenone exerts an ameliorating effect on memory impairment in rats with cerebral infarction.

\section{References}

1 Nagaoka, A., Suno M., Shibouta, M. and Kakihana, M.: Effects of idebenone (CV-2619) on neurological deficits, local cerebral blood flow. and energy metabolism ir. rats with experimental cerebral ischemia. Folia Pharmacol. Japon. 84, 303-309 (1984) (Abs. in English)

2 Yamazaki, N., Take, Y., Nagaoka, A. and Nagawa, Y.: Beneficial effect of idebenone (CV2619) on cerebral ischemia-induced amnesia in rats. Japan. J. Pharmacol. 36, 349-356 (1984)

3 Suno, M. and Nagaoka, A.: Inhibition of lipid peroxidation by a novel compound, idebenone (CV-2619). Japan. J. Pharmacol. 35, 196-198 (1984)

4 Kogure, K., Busto, R., Reinmuth, $O$. and Scheinberg, P.: Energy metabolites, water content, and catecholamine changes in a model of cerebral embolic infarction. Neurology 23, 438-439 (1973)

5 Rick, J.T., Whittle, K.L. and Cross, S.H.: Disruption and facilitation of cue discrimination in the rat by cholinergic agents. Neuropharmacology 20, 747-752 (1981)

6 Righter, $H_{\text {., }}$ van Reizen, $H$. and de Wied, D.: The effects of $\mathrm{ACTH}$ - and vasopressin-analogues on $\mathrm{CO}_{2}$-induced retrograde amnesia in rats. Physiol. Behav. 133, 381-388 (1974)

7 Bookin, H.B.: Effect of lysine vasopressin on pentylenet $€$ trazol-induced retrograde amnesia in rats. Pharmacol. Biochem. Behav. 7, 51-54 (1977) 